\title{
Psychiatric Doubts
}

\author{
Massimo Cocchi ${ }^{1,2}$, Lucio Tonello ${ }^{1}$, Fabio Gabrielli ${ }^{1}$ \\ ${ }^{1}$ Institute "Paolo Sotgiu” for Research in Quantitative \& Quantum Psychiatry \& Cardiology, \\ L.U.de.S. University, Lugano, Switzerland \\ ${ }^{2}$ Department of Veterinary Medical Sciences, University of Bologna, Bologna, Italy \\ Email: massimo.cocchi@unibo.it
}

Received November $16^{\text {th }}$, 2013; revised December $30^{\text {th }}$, 2013; accepted January $9^{\text {th }}$, 2014

\begin{abstract}
Copyright (c) 2014 Massimo Cocchi. This is an open access article distributed under the Creative Commons Attribution License, which permits unrestricted use, distribution, and reproduction in any medium, provided the original work is properly cited. In accordance of the Creative Commons Attribution License all Copyrights (c) 2014 are reserved for SCIRP and the owner of the intellectual property Massimo Cocchi. All Copyright @ 2014 are guarded by law and by SCIRP as a guardian.
\end{abstract}

\section{Introduction}

This decade has clocked the review of the new DSM, the fifth in the series, the instrument considered the "bible" of psychiatry worldwide.

The document, which is accomplished today, reveals firmly rooted in traditional conservative psychiatry, ignoring the progress made by the biological research field. Clearly, the dichotomy between conservative and progressive psychiatry is not over despite the efforts of the scientific research in the fields of psychiatry, brain, neurotransmitters, and quantum computation of the brain and consciousness, i.e., the disciplines that belong to neuroscience. It seems correct, from the point of view of ethics, to remember how it is difficult to think of the research in psychiatry as completely independent of influential external factors.

\section{Recent Major Events in Psychiatry}

Recently, some major events have paved the way for an innovative and deeply critical school of thought which started questioning, at a high intellectual and scientific level, the ideological implications of psychiatric diagnosis and the increasing complexity of the nuances in the classification of the psychiatric disorder. This movement supports the idea of using biological markers in order to get a reliable diagnosis and appropriate care in the first place, limiting in this way the long-standing psychiatric error in the distinction between bipolar disorder and major depression [1], which ranges today from $40 \%$ [1] to $70 \%$ (Tenth World Day for the Prevention of Suicide, Rome, 2012).

The fifth edition has been criticized by a number of authorities, even before it was formally published. The main thrust of criticism has been that changes in the DSM have not kept pace with advances in scientific understanding of psychiatric dysfunction. Another criticism is that the development of DSM-5 was unduly influenced by input from the psychiatric drug industry. A number of scientists have objected that the DSM forces clinicians to make distinctions that are not supported by solid evidence, distinctions that have major treatment implications, including drug prescriptions and the availability of health insurance coverage.

The National Institute of Mental Health in the person of its Director Dr. Thomas R. Insel expresses the following opinions on the new DSM-5 in the course of an interview to the New York Times (2013):

...the manual, which will be published in coming weeks, has a scientific "lack of validity."...

...the manual is the best tool that physicians have at this time, but that is doesn't reflect how complex many mental disorders are...

"As long as the research community takes the DSM to be a bible, we'll never make progress,"

"People think that everything has to match DSM criteria, but you know what? Biology never read that book."

...the National Institute of Mental Health will move away from DSM-5-which he likens to a "dictionary" rather than a bible...

..."In the rest of medicine, this would be equivalent to creating diagnostic systems based on the nature of chest pain or the quality of fever. Indeed, symptom-based diagnosis, once common in other areas of medicine, has been largely replaced in the past half century as we have understood that symptoms alone rarely indicate the best choice of treatment. Patients with mental disorders deserve better.”...

The following sentences were written, as reported in full, in 2010 [2], when there was still a lot of skepticism about the possibility to distinguish between major depression and bipolar disorder thanks to biochemical and molecular evaluations, and there was no official position on the recognition of the biological markers of "Depression", which was nonetheless at the horizon:

"The need for a deep, radical turning point in the world of psychiatry is rapidly growing. Present diagnostic methods cannot continue to be considered acceptable because they are almost completely based on the psychiatrist's opinion, which does not have an objective diagnostic technology and thus has a very high error rate. A debate is essential between the advocates of traditional diagnostic and therapeutic methods and advocates of emerging methods resulting from new discoveries. Major depressive disorder and other related and nonrelated psychiatric conditions are still characterized and defined by descriptive and non-biological criteria, but it is hoped that we can adequately characterize this and other psychiatric disorders with the addition of new quantitative approaches".

However, leading scientists commented on the first results 
obtained in 2008 [4] as reported by an interview to Kary Mullis (Nobel Prize for PCR, 1993) and Stuart Hameroff (Mullis KB: Interview by Marco Pivato. Ma la depressione è nel sangue. Newspaper: La Stampa, insert: TuttoScienze 2008:5. Hameroff SR: Interview by Marco Pivato. Ma la depressione è nel sangue. Newspaper: La Stampa, insert: TuttoScienze 2008:5):

"These possibilities represent a genuine revolution not only in psychiatry but more generally in the worlds of neuroscience and medicine".

Many fundamental scientific works of biological approach to psychiatric illness have been produced in the last thirty years. The relationship between platelet and serotonin and the recognition that platelets are considered neuron ambassadors and that they simulate the behavior of the neuron has been addressed in detail by several authors [3-13].

Observed changes in the serotonergic and microtubular systems in the hippocampus following restraint stress confirm the structural [14,15] and biochemical [16] vulnerability of this area to stressful conditions. Cytoskeletal changes represent a potential new pathway that may increase our understanding of psychiatric disorders. The question of whether or not changes in 5-hydroxytryptamine (5-HT)-serotonin levels are related to changes in the expression of tubulin needs to be assessed by future studies [17]. Already in 1980 it has been shown a relationship between serotonin receptors and lipid membrane fluidity $[18,19]$ : as the membrane lipids become more viscous, the specific binding of serotonin increases steadily. Signal transduction, either through activation of adenylate cyclase by the ligand-receptor complex or by microaggregation of ligand-receptor complexes, is associated with lateral movements of components of the membrane which are determined, at least partially, by lipid fluidity.

The international scientific literature has reported abnormalities in the cAMP signalling cascade of the human brain in suicidal and depressive subjects for over two decades [20-27].

Similarity between humans and pigs in terms of mutual inclination to mood disorders is the recently investigated field [28] concerning puerperal psychosis. Parturition can trigger extreme behavioral disturbances in both women and sows and this can lead, in extreme cases, to infanticide/piglet savaging. Studies have pointed out the existence in both species of a pool of possible genes responsible for the disease.

According to Donati et al. [29] there is a further possible condition: the position of $\mathrm{G} \alpha$ (Gs $\alpha$ in particular) within the lipid raft microdomain and, since it is well known that Gs $\alpha$ protein and tubulin have a connexion [30] it is reasonable to raise the question of a possible link to consciousness according to Hameroff-Penrose Orch theory [31,32]. All these results, together with the many others not cited, could have had practical use and be of great interest in more than one scientific field of application e.g, in the study of new drugs for psychiatric disorders and in the diagnostic evaluation of depressive disorders.

Previously, reference was made to the quantum computation of brain and consciousness, which is likely to emerge strongly in the near future for the scientific understanding of many phenomena related to brain activity and major psychiatric disorders, especially mood disorders.

Two other recent events have advanced hypotheses about the need for a fundamental overhaul of the psychiatric disorder and consciousness, "the Declaration of Palermo" (2013) and "the Declaration of Cambridge” (2012).

"The Declaration of Palermo"
A core international group of investigators, offering expertise in the fields of psychiatry, biochemistry, physics, computational neuroscience, mathematics, philosophy and theology, gathered in Palermo, Sicily, under the auspices of the global QPP (Quantum Paradigm Psychopathology Group) initiative with the aim of assessing the potential relevance of quantum physics and quantum chemistry to mind-brain relations in normal and abnormal states of consciousness applicable to humans and non-human animals.

The Declaration of Palermo was written by Donald Mender and Massimo Cocchi and edited by: Don Michele Aramini, Gustav Bernroider, Francesco Cappello, Fabio Gabrielli, Gordon Globus, Mansoor Malik, Efstratios Manousakis, Kary Mullis, Eliano Pessa, Massimo Pregnolato, Paavo Pylkkänen, Mark M. Rasenick, Lucio Tonello, Jack Tuszynski, Giuseppe Vitiello, Ursula Werneke, Paola Zizzi.

The statement is a prime example of reflection between the quantitative aspects and quantum brain function and the ability to improve therapies in psychiatric disorders concluding:

"Even the absence of highly complex synaptic connections among neurons does not preclude the presence of at least rudimentary phenomenal experience in organisms endowed with superposed microtubular dimers, ordered water, membrane ion channels, and/or crucial lipid raft assemblies connected to selected second messenger systems. In addition, quantum-biophysical aspects of these and/or other yet undiscovered structures and related processes may prove to be potent factors in the deeper etiologies and improved treatments of psychiatric disorders."

"The Declaration of Cambridge" actually unties the concept of consciousness from the abstraction of the old psycho-philosophical custom and recognizes that each animal forms the self-determination of a conscious state even in the absence of structural complexities of the central nervous system, concluding:

..."The absence of a neocortex does not appear to preclude an organism from experiencing affective states. Convergent evidence indicates that non-human animals have the neuroanatomical, neurochemical, and neurophysiological substrates of conscious states along with the capacity to exhibit intentional behaviors. Consequently, the weight of evidence indicates that humans are not unique in possessing the neurological substrates that generate consciousness. Nonhuman animals, including all mammals and birds, and many other creatures, including octopuses, also possess these neurological substrates."

"The Cambridge Declaration” on Consciousness was written by Philip Low and edited by Jaak Panksepp, Diana Reiss, David Edelman, Bruno Van Swinderen, Philip Low and Christof Koch. The Declaration was publicly proclaimed in Cambridge, UK, on July 7, 2012, at the Francis Crick Memorial Conference on Consciousness in Human and non-Human Animals, at Churchill College, University of Cambridge, by Low, Edelman and Koch.

This collection of recent events and advances in biological knowledge of the psychiatric field leads to reflections that, necessarily, affect the bioethical evaluations that relate to the psychiatric patient in his relationship of extreme fragility with the doctor, but also of the doctor with respect to the patient.

Psychiatry is facing today, albeit with resistance and difficulties, a historical contingency that, probably, in the years to come, will be remembered as the turning point that opened up a new dimension of scientific psychiatry and a different relation- 


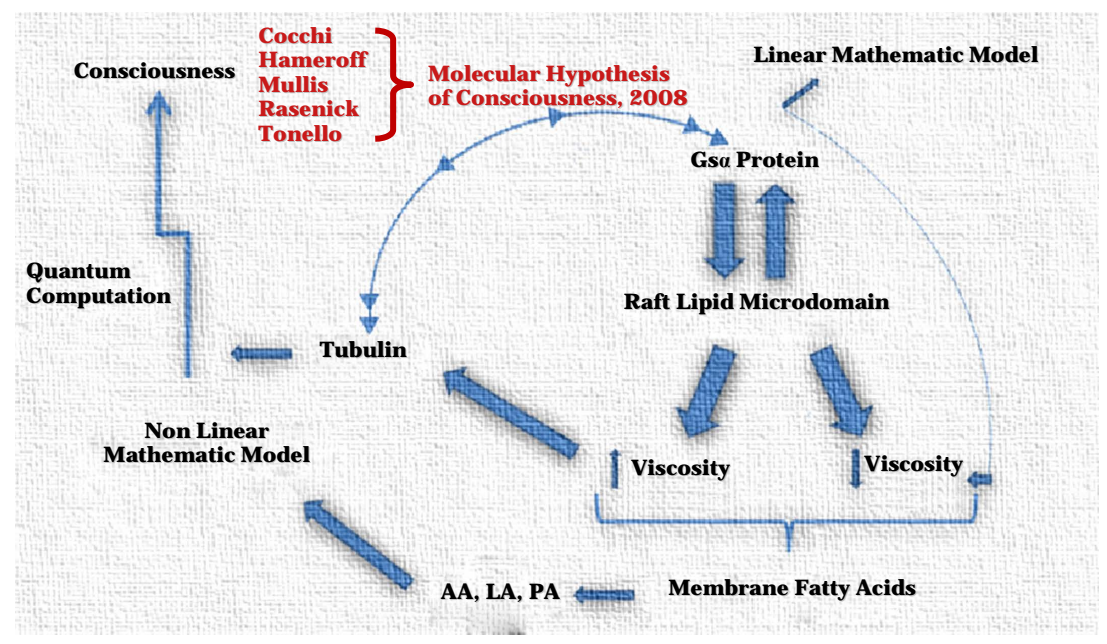

Figure 1.

The road map of the major molecular connection which can be considered for the better understanding of the major psychiatric disorders (Major Depression and Bipolar Disorder) up to consciousness involving the Quantum Chemical Scale of Neural Signals.

ship with the patient.

In this regard, we must recognize that there is, today, the imperative need for new approaches to psychiatric diagnosis and for a new ethical and philosophical evaluation of human being recognizing as essential some aspects of the psychiatrist-patient relationship:

- Priority of the biological fact with respect to symptom

- Embedding of biological data in the experiences of the patient and in the social and cultural expressions of the disease (disease, illness, sickness).

- Integration of psychiatry with other disciplines, against any form of ontological reductionism (need, for example, to make reference to philosophy as transversal knowledge and to complexity of quantum physics and mathematics as inescapable survey instruments).

- Need for rooting of the disease in the socio-anthropological dynamics in place, to assess the gradual nature and texture of their impact on the disorder (the classifications are never pure).

- Revisiting the concept of patient-physician relationship and of empathy in the light of the acquisitions of neuroscience, cognitive science, philosophy of mind.

- Designing courses for psychiatrists on the philosophy of the person, the anthropology of pain, the phenomenology of care.

The path described during a private meeting held in 2008 (Figure 1), contains the summary of the molecular synthesis and the quantum logic that in the coming years could be considered as the trace of the molecular dynamics mapping of the neuron, starting from data on the viscosity of membrane that have now reached concreteness both in animals and humans [33].

\section{REFERENCES}

Bowden, C. L. (2001). Strategies to reduce misdiagnosis of bipolar depression. Psychiatrical Services, 52, 51-55. http://dx.doi.org/10.1176/appi.ps.52.1.51

Cocchi, M., Tonello, L., \& Rasenick, M. M. (2010). Human depression: A new approach in quantitative psychiatry. Annals of General Psy- chiatry, 9, 25. http://dx.doi.org/10.1186/1744-859X-9-25

Cocchi, M., \& Tonello, L. (2010). Bio molecular considerations in Major Depression and Ischemic Cardiovascular Disease. Central Nervous System Agents in Medicinal Chemistry, 10, 97-107. http://dx.doi.org/10.2174/187152410791196378

Cocchi, M., Tonello, L., Tsaluchidu, S., \& Puri, B. K. (2008). The use of artificial neural networks to study fatty acids in neuropsychiatric disorders. BMC Psychiatry, 8, S3.

http://dx.doi.org/10.1186/1471-244X-8-S1-S3

Coleman, M. (1971). Platelet serotonin in disturbed monkeys and children. Clinical Process of Children's Hospital, 27, 187-194.

Takahashi, S. (1976). Reduction of blood platelet serotonin levels in manic and depressed patients. Folia Psychiatrica et Neurologica Japonica, 30, 475-486.

Sthal, S. M. (1977). The human platelet. A diagnostic and research tool for the study of biogenic amines in psychiatric and neurologic disorders. Archives of General Psychiatry, 34, 509-516. http://dx.doi.org/10.1001/archpsyc.1977.01770170019001

Kim, H. L., Plaisant, O., Leboyer, M., Gay, C., Kamal, L., Devynck, M. A., \& Meyer, P. (1982). Reduction of platelet serotonin in major depression (endogenous depression). Comptes Rendus de l'Académie des Sciences III, 295, 619-622.

Dreux, C., \& Launay, J. M. (1985). Blood platelets: Neuronal model in psychiatric disorders. Encephale, 11, 57-64.

Arora, R. C., \& Meltzer, H. Y. (1989). Increased serotonin 2 (5-HT2) receptor binding as measured by $3 \mathrm{H}$-lysergic acid diethylamide (3HLSD) in the blood platelets of depressed patients. Life Science, 44, 725-734. http://dx.doi.org/10.1016/0024-3205(89)90384-6

Thompson, P. (1999). Platelet and erythrocyte membrane and fluidity changes in alcohol dependent patients undergoing acute withdrawal. Alcohol and Alcoholism, 3, 349-354.

http://dx.doi.org/10.1093/alcalc/34.3.349

Camacho, A., \& Dimsdale, J. E. (2000). Platelets and psychiatry: Lessons learned from old and new studies. Psychosomatic Medicine, 62, 326-336.

Plein, H., \& Berk, M. (2001). The platelet as a peripheral marker in psychiatric illness. Clinical and Experimental Pharmacology and Physiology, 16, 229-236.

McEwen, B. S. (1999). Stress and hippocampal plasticity. Annual Review of Neuroscience, 22, 105-122. http://dx.doi.org/10.1146/annurev.neuro.22.1.105

Duman, S. R., Malberg, J., Nagakawa, S., \& D’Sa, C. (2000). Neuronal plasticity and survival in mood disorder. Biological Psychiatry, 48, 732-739. http://dx.doi.org/10.1016/S0006-3223(00)00935-5

Chaouloff, F. (2000). Serotonin, stress and corticoids. Journal of Psy- 
chopharmacology, 14, 139-151. http://dx.doi.org/10.1177/026988110001400203

Bianchi, M., Heidbreder, C., \& Crespi, F. (2003). Cytoskeletal changes in the hippocampus following restraint stress: Role of serotonin and microtubules. Synapse, 49, 188-194. http://dx.doi.org/10.1002/syn.10230

Heron, D. S., Shinitzky, M., Hershkowitz, M., \& Samuel, D. (1980). Lipid fluidity markedly modulates the binding of serotonin to mouse brain membranes. Proceedings of the National Academy of Sciences, 77, 7463-7467. http://dx.doi.org/10.1073/pnas.77.12.7463

Lee, R. E. (1985). Membrane engineering to rejuvenate the ageing brain. Canadian Medical Association Journal, 132, 325-327.

Cowburn, R. F., Marcusson, J. O., Eriksson, A., Wiehager, B., \& O’Neill, C. (1994). Adenylyl cyclase activity and G-protein subunit levels in postmortem frontal cortex of suicide victims. Brain Research, 633, 297-304. http://dx.doi.org/10.1016/0006-8993(94)91552-0

Pacheco, M. A., Stockmeier, C., Meltzer, H. Y., Overholser, J. C., Dilley, G. E., \& Jope, R. S. (1996). Alterations in phosphoinositide signaling and G-protein levels in depressed suicide brain. Brain Research, 723, 37-45. http://dx.doi.org/10.1016/0006-8993(96)00207-7

Dowlatshahi, D., MacQueen, G. M., Wang, J. F., Reiach, J. S., \& Young, L. T. (1999). G proteincoupled cyclic AMP signaling in postmortem brain of subjects with mood disorders: Effects of diagnosis, suicide, and treatment at the time of death. Journal of Neurochemistry, 73, 1121-1126. http://dx.doi.org/10.1046/j.1471-4159.1999.0731121.x

Stewart, R. J., Chen, B., Dowlatshahi, D., MacQueen G. M., \& Young, L. T. (2001). Abnormalities in the cAMP signaling pathway in postmortem brain tissue. Brain Research Bulletin, 55, 625-629. http://dx.doi.org/10.1016/S0361-9230(01)00524-X

Dwivedi, Y., Rizavi, H. S., Conley, R. R., Roberts, R. C., Tamminga, C. A., \& Pandey, G. N. (2002). mRNA and protein expression of selective alpha subunits of $G$ proteins are abnormal in prefrontal cortex of suicide victims. Neuropsychopharmacology, 27, 499-517.

Dwivedi, Y., Rizavi, H. S., Shukla, P. K., Lyons, J., Faludi, G., Palkovits, M., Sarosi, A., Conley, R. R., Roberts, R. C., Tamminga, C. A., \& Pandey, G. N. (2004). Protein kinase A in postmortem brain of depressed suicide victims: Altered expression of specific regulatory and catalytic subunits. Biological Psychiatry, 55, 234-243. http://dx.doi.org/10.1016/j.biopsych.2003.11.003

Pandey, G. N., Dwivedi, Y., Ren, X., Rizavi, H. S., Monda, A. C., Shukla, P. K., \& Conley, R. R. (2005). Brain region specific alterations in the protein and mRNA levels of protein kinase A subunits in the post-mortem brain of teenage suicide victims. Neuropsychopharmacology, 30, 1548-1556. http://dx.doi.org/10.1038/sj.npp.1300765

Poulter, M. O., Du, L., Weaver, I. C. G., Palkovits, M., Faludi, G., Merali, Z., Szyf, M., \& Anisman, H. (2008). GABAA receptor promoter hypermethylation in suicide brain: Implications for the involvement of epigenetic processes. Biological Psychiatics, 64, 645-652. http://dx.doi.org/10.1016/j.biopsych.2008.05.028

Quilter, C. L., Gilbert, C. L., Oliver, G. L., Jafer, O., Furlong, R. A., Blott, S. C., Wilson, A. E., Sargent, C. A., Mileham, A., \& Affara, N. A. (2008). A model for puerperal psychosis. American Journal of Medical Genetics Part B, 147, 1126-1137. http://dx.doi.org/10.1002/ajmg.b.30734

Donati, R. J., Dwivedi, Y., Roberts, R. C., Conley, R. R., Pandey, G. N., \& Rasenick, M. M. (2008). Postmortem brain tissue of depressed suicides reveals increased Gs localization in lipid raft domains where it is less likely to activate adenylyl cyclase. Journal of Neuroscience, 28, 3042-3050. http://dx.doi.org/10.1523/JNEUROSCI.5713-07.2008

Popova, J. S., Greene, A. K., Wang, J., \& Rasenick, M. M. (2002). Phosphatidylinositol 4, 5-bisphosphate modifies tubulin participation in phospholipase C $\beta 1$ signaling. Journal of Neuroscience, 22, 16681678.

Hameroff, S. R., \& Penrose, R. (1996). Orchestrated reduction of quantum coherence in brain microtubules: A model for consciousness. In S. R. Hameroff, A. Kaszniak, \& A. C. Scott (Eds.), Toward a science of consciousness-The first Tucson discussions and debates (pp. 507540). Cambridge, MA: MIT Press.

Hameroff, S. R. (2010). The “conscious pilot”-dendritic synchrony moves through the brain to mediate consciousness. Journal of Biological Physics, 36, 71-93. http://dx.doi.org/10.1007/s10867-009-9148-x

Tonello, L., \& Cocchi, M. (2010). The cell membrane: Is it a bridge from psychiatry to quantum consciousness? Neuro Quantology, 8, 54-60. http://dx.doi.org/10.14704/nq.2010.8.1.268 